\title{
Antiproliferative properties and antioxidant activity of various types of Strobilanthes crispus tea.
}

\begin{abstract}
Regarding to the promising pharmacotherapeutic properties of Strobilanthes crispus (Acanthaceae) plant, we report here, the development of nutraceutical herbal tea from $\mathrm{S}$. crispus young and old leaves and evaluate the potential antiproliferative properties and antioxidant activity in vitro. Unfermented and fermented tea (Camellia sinensis) preparation was applied for development of S. crispus tea. Antiproliferative properties of S. crispus tea extracts were determined by the microculture tetrazolium salt (MTT) assay against human breast cancer cell lines (hormone dependent, MCF-7, non-hormone dependent, MDA-MB231). The results showed that $\mathrm{S}$. crispus tea only inhibit the proliferation of human hormone dependent breast cancer cell lines (MCF-7) but not the non-hormone dependent breast cancer cell lines (MDA-MB-231). The antioxidant activity was determined using FRAP (Ferric Reducing/Antioxidant Power) and DPPH free radical scavenging assay. The results showed that the hot water extract of $\mathrm{S}$. crispus tea showed high antioxidant activity especially $\mathrm{S}$. crispus unfermented tea from old leaves. But the tea from the leaves of C. sinensis displayed better antioxidant activity.
\end{abstract}

Keyword: Antioxidant; Antiproliferative; DPPH free radical scavenging; FRAP; MTT; Strobilanthes crispus; Tea 